\title{
Phosphorus Accumulation in the Dehydrated Peat Soils of the Liwiec River Valley
}

\author{
Marcin Becher', Krzysztof Pakuła'* Dawid Jaremko'1 \\ 1 Institute of Agriculture and Horticulture, Faculty of Agrobioengineering and Animal Sciences, University of \\ Natural Sciences and Humanities in Siedlce, ul. Prusa14, 08-110 Siedlce, Poland \\ * Corresponding author's e-mail: krzysztof.pakula@uph.edu.pl
}

\begin{abstract}
The aim of the research was to complement the knowledge on profile distribution and accumulation of phosphorus forms in the soils changed under the influence of secondary organic matter transformation process in dehydrated peatlands. The soil research was carried out in the upper Liwiec river valley in the middle-east of Poland. In the soil material taken from the moorsh (M1, M2, M3) and peat $(\mathrm{O})$ horizons of the Murshic Histosols, the physical and chemical properties were determined and the soil phosphorus fractions with different activity in the environment by sequential extraction method were separated. The profile distribution of the total phosphorus content (TP) and values of carbon/phosphorus (TC/TP) ratio were characteristic for dehydrated peat soils included in the secondary transformation process $(\mathrm{M} 1>\mathrm{M} 2>\mathrm{M} 3>0)$. This process also increased the contribution of the available phosphorus forms (NH4Cl-P), forms bound on the surface of iron (III) and manganese (IV) oxides and hydroxides (redox-P), as well as mineral (mHCl-P) and organic (oHCl-P) forms separated by $0.5 \mathrm{M} \mathrm{HCl}$. Significant accumulation of the phosphorus compounds in the moorsh horizons of the investigated soils can be considered as a potential threat to the natural environment of the studied area due to the risk of decomposition of the phosphorus compounds when the area will be rehydrated.
\end{abstract}

Keywords: peatlands soils, secondary transformation process, phosphorus forms, soil horizon

\section{INTRODUCTION}

The area of soils developed from peat in Poland is just over 1.2 million ha, corresponding to about $4 \%$ of the country's area (Ilnicki, Szajdak 2016, Łachacz, Kalisz 2016). The condition for improving the production characteristics of peat soils (increasing the production of cattle feed) was to reduce the groundwater level, which resulted in a reduction of the protective effect of water in relation to the peat organic matter. Dehydration changes the direction of soil cover evolution in peatlands, i.e. the degradation of organic matter and reconstruction of the physical and chemical properties of the soil increases. As a result of this transformation, a wall with aggregate structure and increased amount of humus substances is produced in relation to the deeper layers of the peat (Becher 2013, Glina et al. 2016, Bader et al. 2018).
Dehydrated peat soils, which are a "boundary zone" between terrestrial and aquatic ecosystems, are often characterized by excessive phosphorus accumulation. This poses a risk of phosphorus dispersion, including migration to ground waters, where this element (besides nitrogen) is responsible for the eutrophication process. In addition, dehydrated organic soils are characterized by a high variability of oxidation and reduction conditions, which in turn has a significant effect on the phosphorus forms and its solubility (Litaor et al. 2004, Sapek 2014, Becher et al. 2018). As a result of the peat organic matter mineralization, it is possible to transform the organic phosphorus compounds into mineral compounds susceptible to release when the redox potential changes. Reirrigation of drained peatlands can lead to the release of phosphorus in soils (Zak, Gelbrecht 2007, Jordan et al. 2007, Kang et al. 2009). The potential scale and mechanisms of this phenomenon 
in the soils of dehydrated Polish peatlands are not fully understood. This research problem is particularly important in view of attempts to renaturalize wetland areas, which would involve re-irrigating them.

The aim of the research was to complement the knowledge on the amount and profile distribution of the phosphorus forms in soil horizons resulting from the secondary transformation of organic matter in dehydrated peatlands, and assessment of potential environmental effects of soil phosphorus transformation, migration and accumulation.

\section{MATERIALS AND METHODS}

The soil research was carried out on peatlands in the upper Liwiec river valley (left tributary of the Bug river) nearby the Klimonty village (52 $\left.{ }^{\circ} 10^{\prime} 48^{\prime \prime} \mathrm{N} 22^{\circ} 31^{\prime} 39^{\prime \prime} \mathrm{E}\right)$ and the Radzików Wielki village (52 $08^{\prime} 32^{\prime \prime} \mathrm{N} 22^{\circ} 31$ '39' $\left.\mathrm{E}\right)$ in the middle-east of the Mazowieckie Voivodeship (Poland). The Liwiec river valley is the main wetland area of the Siedlecka Upland, which was formed during the Warta glaciation. These peatlands were drained in the 1960s. Currently, they are intensively used for agriculture and are subject to an intensive secondary transformation process.

The soil samples were collected from 5 soil profiles classified according to the Polish Soil Classification (SSSP 2011), as Murshic Histosols, made from reed peat ( 3 profiles) and alder peat ( 2 profiles). The laboratory tests were carried out on material taken from 25 soil horizons (Table1).

The representative soil samples were dried at $40{ }^{\circ} \mathrm{C}$ and spread in a porcelain mortar $(\varnothing=0.25 \mathrm{~mm})$. The analyses on the following parameters were conducted:

- ash content, after roasting the soil sample in the muffle furnace, at $600{ }^{\circ} \mathrm{C}$;
- total content of carbon (TC) and nitrogen (TN) was determined on $\mathrm{CHN}$ elementary analysis autoanalyzer (thermal conductivity detector, acetanilide as a reference material);

- total content of phosphorus (TP) and Fe, Mn, $\mathrm{Al}, \mathrm{Ca}$ (elements potentially important for phosphorus binding processes) was determined on inductively excited plasma atomic emission spectrometer (ICP-AES). The samples were mineralized in a microwave mineralizer in an aqua regia solution;

- carbon content in the $0.1 \mathrm{M} \mathrm{NaOH}$ (HS-C) extract $(\mathrm{m} / \mathrm{v}=1 / 25$, extraction time $24 \mathrm{~h})$, the extract was filtered through a cellulose membrane filter, the carbon in the extract was determined by the oxidation-titration method.

In the moorsh horizons, the phosphorus enrichment index (EI-P)) were calculated in relation to the average content of this element in peat horizons ( $\mathrm{Oa}$ and $\mathrm{Oe}$ ).

The $\mathrm{pH}$ value was determined with the potentiometric method, after flooding the fresh soil sampling with $1 \mathrm{M} \mathrm{KCl}(\mathrm{v} / \mathrm{v}=1 / 1)$. A sequential analysis of phosphorus compounds was also performed for the fresh samples. The method of sequential chemical fractionation of phosphorus compounds, modified for peat material tests, proposed by Jordan et al. (2007) was used to study the phosphorus speciation. The selective ability to secrete specific organic and inorganic compounds in the sequential analysis by the extraction solutions used allowed to separate the following 7 forms (operational fractions) of soil phosphorus: step $1-\mathrm{NH}_{4} \mathrm{Cl}-\mathrm{P}$ - available (labile), loosely bound or absorbed forms, extracted by $1 \mathrm{M}$ $\mathrm{NH}_{4} \mathrm{Cl}$, step 2 - redox-P - forms sensitive to the change of redox potential, bound on the surface of hydrated iron (III) and manganese (IV) oxides and hydroxides, released under reduction conditions, extracted by $0,1 \mathrm{M} \mathrm{Na}_{2} \mathrm{~S}_{2} \mathrm{O}_{4}-\mathrm{NaHCO}_{3}$, step 3 - HCl-P - mineral and organic forms separated

Table 1. Characteristics of tested soils horizons

\begin{tabular}{|c|c|c|l|}
\hline $\begin{array}{c}\text { Symbol } \\
\text { of soils horizon }\end{array}$ & $\begin{array}{c}\text { Number } \\
\text { of horizon }\end{array}$ & $\begin{array}{c}\text { Thickness } \\
\text { (mean) cm }\end{array}$ & \multicolumn{1}{|c|}{ Morphological features } \\
\hline M1 & 5 & 10.2 & $\begin{array}{l}\text { Moorsh (Muck). The upper horizon is very strongly overgrown with plant roots, } \\
\text { with a fine granular structure. }\end{array}$ \\
\hline M2 & 5 & 11.5 & Moorsh (Muck). Lying below the M1 horizon with a medium granular structure. \\
\hline M3 & 5 & 19.2 & $\begin{array}{l}\text { Moorsh (Muck). Lying below the M2 horizons. Intensively cracked organic } \\
\text { mass with preserved peat features and the illusive displacement of humus } \\
\text { from the higher horizons. }\end{array}$ \\
\hline Oa & 6 & 34.2 & Reed peat, Fibric, hemic, H4-H6 on the von Post scale \\
\hline Oe & 4 & 16.5 & Alder peat, the most decomposed, sapric, H7-H8 on the von Post scale. \\
\hline
\end{tabular}


by $0.5 \mathrm{M} \mathrm{HCl}$, including: step $4-\mathrm{mHCl}-\mathrm{P}$ - forms bound by metal oxides ( $\mathrm{Fe}, \mathrm{Al}$ and $\mathrm{Mn}$ ), phosphorus in apatites and carbonates, determined in the extract with $0.5 \mathrm{M} \mathrm{HCl}$ by means of the colorimetric method, used ammonium molybdate (VI) and photorex - to form colored phosphate anion complexes (V); tin (II) chloride - for reduction, and step 5 - oHCl-P - phosphorus forms in organic compounds, labile, released under acidification conditions, calculated from the formula: oHCl-P $=\mathrm{HCl}-\mathrm{P}-\mathrm{mHCl}-\mathrm{P}$, step $6-\mathrm{NaOH}-$ $\mathrm{P}$ - forms bound by humus substances and other polymorphic forms of phosphorus extracted by $1 \mathrm{M} \mathrm{NaOH}$, step 7 - res-P - phosphorus in the residual fraction (in the post-extraction residue), very stable organic and mineral phosphorus compounds, calculated from the formula: res- $\mathrm{P}=\mathrm{TP}-$ $\left(\mathrm{NH}_{4} \mathrm{Cl}-\mathrm{P}+\right.$ redox-P $\left.+\mathrm{HCl}-\mathrm{P}+\mathrm{NaOH}-\mathrm{P}\right)$.

Extraction $(\mathrm{m} / \mathrm{v}=1 / 5)$ was performed in polypropylene centrifugal flasks on a shaker type mixer (extraction time: $0.5 \mathrm{~h}$ for $\mathrm{NH}_{4} \mathrm{Cl}-\mathrm{P}$ and redox-P fractions and $24 \mathrm{~h}$ for $\mathrm{HCl}-\mathrm{P}$ and $\mathrm{NaOH}-$ $\mathrm{P}$ ones). Between each sequential extraction step, the supernatant was separated from the solid phases by centrifuging for $10 \mathrm{~min}$ at $5000 \mathrm{rpm}$ and was filtered through cellulose filters. The residue was washed twice with deionized water $\left(10 \mathrm{~cm}^{3}\right)$, centrifuged and filtered. The essential extract and deionized water after rinsing were collected in a volumetric flask. The content of phosphorus fractions (except mHCl-P fraction) in particular extracts was determined by means of the ICP-AES method. The accuracy of the measurements was determined with the addition of a standard into each analyzed sample. The analyses included the control samples consisting of chemical reagents (corresponding to fractions). The percentage contribution of separated seven fractions of $\mathrm{P}$ in relation to its content in an aqua regia solution (TP) were calculated.

The statistical calculations were conducted with the STATISTICA 13 PL (TIBCO Software, PaloAlto, USA) software. The values of the examined parameters in the soil horizons were compared with one-factor variance analysis and Tukey's post-hoc test (for different n). Significant statistical differences were assumed at the level of $\mathrm{p}=0.05$. The relationships between the examined parameters were expressed as a simple correlation coefficient (r).

\section{RESULTS AND DISCUSSION}

\section{Soil properties}

Formation of moorsh horizons (M1 and M2) with agranular structure was a very clear property of the structure of soils selected for the study. The third moorsh horizon (M3), although it retained the morphological characteristics of peat, was built of clearly cracked organic matter. The measurement of the $\mathrm{pH}$ value showed small variability of this parameter in the studied horizons of soil, beneficial for the meadow vegetation used for agriculture.

Laboratory tests confirmed the distinctiveness of the formed moorsh in relation to peat (Table 2). Compared to peat, the moorsh horizons were characterized by a higher ash content and lower carbon content, as well as lower values of the carbon to nitrogen ratio.

Many studies have shown that as a result of intensive aerobic decomposition of organic matter and depletion of carbon compounds in soil, the carbon/nitrogen ratio is significantly narrowed during the secondary transformation process (De Van Riet et al. 2013, Glina et al. 2016). The values of these ratios decreased in the studied soils according to the degree of organic matter processing, i.e. from the highest values in the peat horizons to significantly lower values in the moorsh horizons. The physical and chemical parameters of the top moorsh horizons obtained for physical and chemical parameters prove the eutrophy of the soil environment, high biological activity

Table 2. Some properties of the investigated soils

\begin{tabular}{|c|c|c|c|c|c|}
\hline Soil horizon & $\mathrm{pH}$ & Ash $(\%)$ & $\mathrm{TC}\left(\mathrm{g} \cdot \mathrm{kg}^{-1}\right)$ & $\mathrm{TC} / \mathrm{TN}$ & $\mathrm{HS}-\mathrm{C}(\% \mathrm{TC})$ \\
\hline $\mathrm{M} 1$ & $5.53-6.91^{*}$ & $24.3^{\mathrm{c}} \pm 3.40^{* *}$ & $400^{\mathrm{a}} \pm 21.4$ & $11.2^{\mathrm{a}} \pm 0.34$ & $33.5^{\mathrm{b}} \pm 8.61$ \\
\hline $\mathrm{M} 2$ & $5.60-6.45$ & $21.4^{\mathrm{bc}} \pm 5.87$ & $427^{\mathrm{ab}} \pm 33.1$ & $12.2^{\mathrm{ab}} \pm 1.17$ & $31.8^{\mathrm{b}} \pm 7.83$ \\
\hline $\mathrm{M} 3$ & $5.72-6.32$ & $13.8^{\mathrm{a}} \pm 1.72$ & $488^{\mathrm{c}} \pm 8.35$ & $13.7^{\mathrm{b}} \pm 0.43$ & $26.8^{\mathrm{ab}} \pm 8.49$ \\
\hline Oe & $5.84-6.02$ & $11.6^{\mathrm{a}} \pm 1.93$ & $515^{\mathrm{c}} \pm 22.9$ & $16.4^{\mathrm{c}} \pm 1.19$ & $15.6^{\mathrm{a}} \pm 2.23$ \\
\hline Oa & $5.93-6.20$ & $16.8^{\mathrm{ab}} \pm 0.92$ & $474^{\mathrm{bc}} \pm 15.2$ & $16.3^{\mathrm{c}} \pm 0.77$ & $24.8^{\mathrm{ab}} \pm 6.81$ \\
\hline
\end{tabular}

*range; ${ }^{* *}$ mean value $\pm \mathrm{SD}$; $\mathrm{a}, \mathrm{b}, \mathrm{c}-$ homogeneous means groups at $\mathrm{p}=0.05$ (values marked by the same letter do not differ statistically significantly) 
and favorable conditions for the organic matter decomposition processes (Becher 2013, Ilnicki, Szajdak 2016).

The carbon extracted from the studied soil samples with an alkaline solution $(0.1 \mathrm{M} \mathrm{NaOH})$ represents humus substances and can be a determinant of the degree of organic matter decomposition of the studied soil horizons. The highest share of coal in $0.1 \mathrm{M} \mathrm{NaOH}$ extract was found in the moorsh horizons. Among the peat horizons, a higher share of HS-C was found in alder peats (H7-H8) than reed peats (H4-H6).

\section{Phosphorus accumulation}

There was a very diversified phosphorus content in the studied soil horizons (Table 3). It was defined within a wide range of 0.420 $2.38 \mathrm{~g} \cdot \mathrm{kg}^{-1}$. In relation to carbon, the content of this biogenic element was characterized by a greater variability. In all the profiles studied, there was a clear trend of the phosphorus content decreasing with soil depth. On the basis of the phosphorus content, the studied soil horizons of individual soils can be arranged in the following decreasing accumulation of this element: $\mathrm{M} 1>\mathrm{M} 2>\mathrm{M} 3>\mathrm{Oa}>$ Oe.

A statistical analysis showed that in the studied population of soil horizons, in terms of the

Table 3. Total content of phosphorus (TP), enrichment index of phosphorus (EI-P) and carbon to phosphorus ratio (TC/TP) in the investigated soils

\begin{tabular}{|c|c|c|c|}
\hline $\begin{array}{c}\text { Soil } \\
\text { horizon }\end{array}$ & TP $\left(\mathrm{g} \cdot \mathrm{kg}^{-1}\right)$ & EI-P & TC/TP \\
\hline M1 & $2.04^{\mathrm{c}} \pm 0.335^{*}$ & $3.39^{\mathrm{c}} \pm 1.02$ & $201^{\mathrm{a}} \pm 39.3$ \\
\hline $\mathrm{M} 2$ & $1.46^{\mathrm{b}} \pm 0.307$ & $2.36^{\mathrm{b}} \pm 0.51$ & $301^{\mathrm{a}} \pm 58.3$ \\
\hline $\mathrm{M} 3$ & $0.869^{\mathrm{a}} \pm 0.171$ & $1.39^{\mathrm{a}} \pm 0.18$ & $581^{\mathrm{b}} \pm 121$ \\
\hline $\mathrm{Oe}$ & $0.519^{\mathrm{a}} \pm 0.095$ & - & $1018^{\mathrm{c}} \pm 186$ \\
\hline Oa & $0.818^{\mathrm{a}} \pm 0.085$ & - & $584^{\mathrm{b}} \pm 63.0$ \\
\hline
\end{tabular}

${ }^{*}$ Mean value \pm SD; $\mathrm{a}, \mathrm{b}, \mathrm{c}-$ homogeneous means groups at $\mathrm{p}=0.05$ (values marked by the same letter do not differ statistically significantly) phosphorus content, the horizons of M1 and M2 constitute separate groups, significantly different from each other and from the other soil horizons. No significant differences between M3 and the peat horizons were found (Table 3).

A characteristic property of the organic soils studied is a steep decrease in the phosphorus content in the peat parent horizons, in relation to the moorsh surface horizons. This is reflected in the phosphorus enrichment index (EI-P) which takes values clearly higher than one. Taking into account the value of the enrichment factor, the moorsh horizons of the studied soils can be ranked as follows: M1 $>$ M2 $>$ M3 (Table 3).

There was a very varied value found in the profiles expressing the ratio of carbon to phosphorus mass (TC/TP) in the studied soils (Table 3). Between the surface moorsh horizons (M1 and M2) and peat ones, there is a steep (several times) increase in this ratio.

The observed accumulation and distribution of TP in particular soil horizons and the values of the carbon/phosphorus ratio are characteristic for dehydrated peat soils included in the secondary transformation process (Otabbong et al. 2009, Worrall et al. 2016, Becher et al. 2018).

The values of correlation coefficients indicate that the accumulation of phosphorus in the studied soil horizons is significantly related to the decomposition of organic matter and the diagenesis of the soil material occurring in the secondary transformation process (Table 4). Significantly more soil phosphorus is accumulated in the horizons with higher ash content and soil mass density. Moreover, significant correlations were found between the carbon content, TC/TN ratio and the share of humus substances, which clearly indicates the relationship between the phosphorus accumulation and organic matter transformations. The correlations of phosphorus with the elements for which the importance of soil phosphorus binding processes (calcium, magnesium, iron, aluminum and manganese) has been proven are also

Table 4. Value of correlation coefficients between total phosphorus content (TP), carbon to phosphorus ratio (TC/TP) and properties of the investigated soils

\begin{tabular}{|c|c|c|c|c|c|}
\hline Parameter & TP & TC/TP & Parameter & TP & TC/TP \\
\hline Ash & 0.802 & -0.805 & $\mathrm{Ca}$ & -0.176 & -0.026 \\
\hline $\mathrm{pH}$ & 0.198 & -0.206 & $\mathrm{Mg}$ & -0.289 & 0.469 \\
\hline $\mathrm{TC}$ & -0.846 & 0.851 & $\mathrm{Fe}$ & 0.661 & -0.793 \\
\hline $\mathrm{TC} / \mathrm{TN}$ & -0.834 & 0.855 & $\mathrm{Al}$ & 0.585 & -0.558 \\
\hline HS-C & 0.696 & -0.748 & $\mathrm{Mn}$ & 0.718 & -0.633 \\
\hline
\end{tabular}

Critical values $(n=25): 0.396$ at $p=0.05 ; 0.505$ at $p=0.01$ 
presented (Kalembasa, Becher 2010, Balemili Negisho 2012, Sapek 2012). Among this group of elements, significant positive correlations with the phosphorus content were found for the $\mathrm{Fe}, \mathrm{Al}$ and $\mathrm{Mn}$ content in the investigated soils.

Particularly strong correlations (high coefficient values) in the studied soils were found for soil properties and carbon/phosphorus ratio (TC/ TP). The decomposition of organic matter and the secondary transformation process of the studied soils is therefore closely related to the narrowing of the carbon-to-nitrogen ratio and carbon-tophosphorus ones.

\section{Soil phosphorus fractions}

The content of the available phosphorus forms $\left(\mathrm{NH}_{4} \mathrm{Cl}-\mathrm{P}\right)$ was the lowest of all forms of phosphorus and was below $23.4 \mathrm{mg} \cdot \mathrm{kg}^{-1}$, at a contribution of less than $1.11 \%$ TP. In the studied soils, the upper moorsh horizons (M1) were clearly characterized by the highest content of this form of phosphorus. The amount of $\mathrm{NH}_{4} \mathrm{Cl}-\mathrm{P}$ decreased with depth. The $\mathrm{NH}_{4} \mathrm{Cl}-\mathrm{P}$ content significantly correlated with soil properties (Table 5), which suggests that the processes of organic matter decomposition associated with the secondary transformation process have a significant positive effect on the amount of the available phosphorus forms. Moreover, it was found that the decrease in the studied soil horizon acidification may significantly affect the increase in the available phosphorus fraction contribution.

Jordan et al. (2007), Castillo and Wright (2008), Becher et al. (2018) found a similar amount of phosphorus to that found in the studied soils of the Liwiec river valley. These authors suggest that the $\mathrm{NH}_{4} \mathrm{Cl}-\mathrm{P}$ fraction, due to its low concentration, does not pose a threat to phosphorus dispersion and migration to ecosystems adjacent to the wetland areas.

The phosphorus forms sensitive to the changes under the oxidation-reduction conditions (redoxP) were characterized by high variability - their share in the total content of phosphorus in the examined soil horizons ranged from 2.96 to $12.6 \%$ (Table 5). The greatest amount of this phosphorus form was found in the surface moorsh horizons (M1). There was a clear tendency for this form of phosphorus to decrease with the depth of the soil. Statistically significant differences in the content
Table 5. Separated phosphorus fractions in the investigated soils

\begin{tabular}{|c|c|c|c|}
\hline Fraction & $\begin{array}{c}\text { Soil } \\
\text { horizon }\end{array}$ & $\begin{array}{c}\text { Content (mg · } \\
\left.\mathrm{kg}^{-1}\right)\end{array}$ & Contribution (\% TP) \\
\hline \multirow{5}{*}{$\mathrm{NH}_{4} \mathrm{Cl}-\mathrm{P}$} & M1 & $17.1^{c} \pm 4.14^{*}$ & $0.843^{b} \pm 0.186$ \\
\hline & M2 & $9.26^{\mathrm{b}} \pm 2.68$ & $0.660^{\mathrm{ab}} \pm 0.241$ \\
\hline & M3 & $4.81^{a} \pm 1.14$ & $0.558^{\mathrm{ab}} \pm 0.112$ \\
\hline & $\mathrm{Oe}$ & $2.70^{\mathrm{a}} \pm 0.897$ & $0.517^{a} \pm 0.160$ \\
\hline & $\mathrm{Oa}$ & $2.59 a \pm 0.260$ & $0.318^{a} \pm 0.009$ \\
\hline \multirow{5}{*}{ redox-P } & M1 & $222^{\mathrm{d}} \pm 37.3$ & $11.0^{\mathrm{b}} \pm 1.31$ \\
\hline & M2 & $147^{\circ} \pm 49.7$ & $9.96^{b c} \pm 1.51$ \\
\hline & M3 & $88.9^{b c} \pm 29.5$ & $10.2^{\mathrm{bc}} \pm 2.27$ \\
\hline & $\mathrm{Oe}$ & $27.2^{\mathrm{a}} \pm 11.5$ & $5.18^{a} \pm 1.77$ \\
\hline & $\mathrm{Oa}$ & $56.4^{\mathrm{ab}} \pm 3.79$ & $6.94^{\mathrm{ac}} \pm 0.622$ \\
\hline \multirow{5}{*}{$\mathrm{HCl}-\mathrm{P}$} & M1 & $543^{c} \pm 138$ & $26.4^{\mathrm{b}} \pm 3.86$ \\
\hline & M2 & $294^{b} \pm 56.4$ & $20.3^{a} \pm 2.12$ \\
\hline & M3 & $156^{\mathrm{a}} \pm 42.7$ & $17.8^{\mathrm{a}} \pm 2.31$ \\
\hline & $\mathrm{Oe}$ & $84.8^{a} \pm 16.0$ & $16.4^{a} \pm 2.14$ \\
\hline & $\mathrm{Oa}$ & $126^{\mathrm{a}} \pm 25.8$ & $15.4^{a} \pm 1.88$ \\
\hline \multirow{5}{*}{$\mathrm{mHCl}-\mathrm{P}$} & M1 & $402^{c} \pm 104$ & $19.5^{\mathrm{d}} \pm 2.69$ \\
\hline & M2 & $243^{b} \pm 60.4$ & $16.7^{\text {cd }} \pm 2.42$ \\
\hline & M3 & $125^{\mathrm{a}} \pm 46.1$ & $14.0^{\mathrm{bc}} \pm 2.84$ \\
\hline & $\mathrm{Oe}$ & $58.2^{\mathrm{a}} \pm 10.3$ & $11.3^{\mathrm{ab}} \pm 1.11$ \\
\hline & $\mathrm{Oa}$ & $73.8^{a} \pm 9.79$ & $9.18^{a} \pm 2.07$ \\
\hline \multirow{5}{*}{ oHCl-P } & M1 & $141^{\mathrm{b}} \pm 89.6$ & $6.88^{a} \pm 3.90$ \\
\hline & M2 & $51.1^{a} \pm 15.6$ & $3.60^{a} \pm 1.33$ \\
\hline & M3 & $31.4^{\mathrm{a}} \pm 6.49$ & $3.82^{\mathrm{a}} \pm 1.40$ \\
\hline & $\mathrm{Oe}$ & $26.6^{\mathrm{a}} \pm 7.40$ & $5.14^{a} \pm 1.33$ \\
\hline & $\mathrm{Oa}$ & $52.5^{a} \pm 35.4$ & $6.18^{a} \pm 3.78$ \\
\hline \multirow{5}{*}{$\mathrm{NaOH}-\mathrm{P}$} & M1 & $1066^{c} \pm 188$ & $52.2^{\mathrm{a}} \pm 3.51$ \\
\hline & M2 & $796^{b} \pm 157$ & $54.6^{a} \pm 2.88$ \\
\hline & M3 & $464^{\mathrm{a}} \pm 77.6$ & $53.7^{\mathrm{a}} \pm 3.43$ \\
\hline & $\mathrm{Oe}$ & $290^{\mathrm{a}} \pm 58.6$ & $55.6^{a} \pm 1.74$ \\
\hline & $\mathrm{Oa}$ & $470^{\mathrm{a}} \pm 67.7$ & $57.3^{a} \pm 2.65$ \\
\hline \multirow{5}{*}{ res-P } & M1 & $195^{b} \pm 23.3$ & $9.62^{\mathrm{a}} \pm 1.00$ \\
\hline & M2 & $214^{b} \pm 61.5$ & $14.5^{\mathrm{ab}} \pm 1.04$ \\
\hline & M3 & $155^{\mathrm{ab}} \pm 34.4$ & $17.7^{\mathrm{bc}} \pm 1.17$ \\
\hline & $\mathrm{Oe}$ & $115^{\mathrm{a}} \pm 26.3$ & $22.3^{c} \pm 3.73$ \\
\hline & $\mathrm{Oa}$ & $162^{\mathrm{ab}} \pm 22.4$ & $20.1^{c} \pm 4.02$ \\
\hline
\end{tabular}

${ }^{*}$ Mean value \pm SD; a, b, c, d - homogeneous means groups at $\mathrm{p}=0.05$ (values marked by the same letter do not differ statistically significantly)

occur between moorsh (M1, M2, M3) and peat horizons, as well as within the moorsh ones.

The correlation coefficients indicate that the amount of phosphorus in the fraction sensitive to the change of redox potential is significantly related to the secondary transformation process. This is evidenced by the values and signs of the coefficients for the properties typically variable in the secondary transformation process. Particularly high values for the coefficient were found for this fraction content with the total phosphorus 
content (positive correlation) and the values of $\mathrm{TC} / \mathrm{TP}$ and TC/TN ratio (negative correlation). Moreover, a positive correlation was found with the total content of iron, aluminum and manganese in the soil (Table 6).

Scientific studies have shown that strong binding by iron (III) and manganese (III) oxides and hydroxides is crucial for the phosphorus accumulation in this fraction. Reduction of these compounds, e.g. when the land is re-irrigated, is likely to be an important mechanism for releasing phosphorus and increasing the risk of its migration to neighboring ecosystems (Jordan et al. 2007, Zak et al. 2014, Becher et al. 2018). This mechanism has also been confirmed in many controlled incubation studies (Forsmann, Kjaergaard 2014).

A solution of $0.5 \mathrm{M} \mathrm{HCl}$ was extracted from 13.3 to $32.3 \%$ of total phosphorus content (Table 5). The M1 horizons, which differ significantly from other soil horizons, are the most enriched with HCl-P form of phosphorus. In this fraction, in all soil samples tested, the content of mineral phosphorus forms (mHCl-P) was higher than the forms in the organic compounds (oHCl-P). The highest content of mineral forms of phosphorus of the $0.5 \mathrm{M} \mathrm{HCl}$ fraction was found in the M1 horizons. A significant difference was also found between the moorsh M2 and peat horizons (Table 5). The content of organic forms of phosphorus extracted with $0.5 \mathrm{M}$ $\mathrm{HCl}$ was characterized by a greater variability than mineral forms. Despite the high dynamics of phosphorus in this fraction, no significant differences were found between soil horizons in the contribution of oHCl-P fraction in the total phosphorus content (TP).

The correlation coefficients presented in Table 6 provide the information about the significant effect of organic matter transformation on the accumulation and the contribution of phosphorus fractions extracted with $0.5 \mathrm{M} \mathrm{HCl}$. Particularly high values of the coefficient with soil properties were noted for the amount and contribution of mHCl-P. This suggests that the process of decomposing organic matter in the moorsh horizons significantly contributes to the increase in the amount of mHCl-P in soils.

Jordan et al. (2007) and Meissner et al. (2008) claim that phosphorus representing mineral and organic compounds extracted with $0.5 \mathrm{M} \mathrm{HCl}$ in dehydrated and well decomposed peats may be released in the event of repeated water accumulation in peats.

The forms of phosphorus bound by humus substances $(\mathrm{NaOH}-\mathrm{P})$ were the most important fraction in terms of quantity. Using extraction with $1.0 \mathrm{M} \mathrm{NaOH}, 54.6 \%$ of total phosphorus content was isolated from the soil horizons (Table 5). The greatest amount of this fraction was found in the M1 horizons. Despite the high dynamics of variation in the amount of phosphorus bound by humus substances, the contribution of these forms in the total phosphorus content was less variable in the studied soil horizons.

The correlation coefficients suggest high importance of organic matter humification in the phosphorus binding processes of the studied soils (Table 6). Positive and high coefficient values for TP and NaOH-P indicate that the enrichment of soil horizons with phosphorus occurs mainly in the form of humic substances. At the same time, the contribution of these forms in the total phosphorus content decreases slightly, but at a statistically significant level. This is the opposite of redox-P and $\mathrm{HCl}-\mathrm{P}$, where an increase in the amount of these forms simultaneously resulted in an increase in their contribution in TP. This may suggest an increasing importance of phosphorus binding in mineral compounds (mainly by oxides and hydroxides of $\mathrm{Fe}, \mathrm{Mn}$ and $\mathrm{Al}$ ) in the moorsh horizons, at the expense of binding by humic substances.

Table 6. Value of correlation coefficients between the content of phosphorus fraction and selected properties of the investigated soils

\begin{tabular}{|c|c|c|c|c|c|c|c|}
\hline Fraction & Ash & $\mathrm{pH}$ & $\mathrm{TC}$ & $\mathrm{TC} / \mathrm{TN}$ & $\mathrm{HS}-\mathrm{C}$ & $\mathrm{TP}$ & $\mathrm{TC} / \mathrm{TP}$ \\
\hline $\mathrm{NH}_{4} \mathrm{Cl}-\mathrm{P}$ & 0.844 & 0.465 & -0.871 & -0.848 & 0.456 & 0.893 & -0.756 \\
\hline redox-P & 0.700 & 0.063 & -0.775 & -0.825 & 0.758 & 0.965 & -0.853 \\
\hline $\mathrm{HCl}-\mathrm{P}$ & 0.742 & 0.281 & -0.802 & -0.782 & 0.590 & 0.964 & -0.789 \\
\hline $\mathrm{mHCl}-\mathrm{P}$ & 0.742 & 0.164 & -0.793 & -0.815 & 0.680 & 0.970 & -0.799 \\
\hline $\mathrm{oHCl}-\mathrm{P}$ & 0.527 & 0.483 & -0.592 & -0.475 & 0.200 & 0.671 & -0.536 \\
\hline $\mathrm{NaOH}-\mathrm{P}$ & 0.833 & 0.194 & -0.858 & -0.840 & 0.686 & 0.991 & -0.885 \\
\hline res-P & 0.592 & 0.001 & -0.630 & -0.590 & 0.739 & 0.763 & -0.788 \\
\hline
\end{tabular}

Critical values $(n=25): 0.396$ at $p=0.05 ; 0.505$ at $\mathrm{p}=0.01$ 
The obtained results indicate that in the surface moorsh horizons constituting the rhizosphere, the released phosphorus compounds in the mineralization processes of organic matter and other sources (e.g. mineral fertilizing) are bound mainly by humic substances, as well as iron, manganese and aluminum compounds. This suggestion is confirmed by the scientific research conducted by Graham et al. (2005), Kang et al. (2009), Becher et al. (2018).

The significant effect of the organic matter decomposition process on the content of the phosphorus bound by humic substances is confirmed by significant values of the correlation coefficient with physical and chemical parameters characteristically variable in the transformation process of peat soils occurring after their dehydration (Table 6).

The phosphorus compounds of the residual fraction (res-P, in the post-extraction residue) in the studied soil horizons constituted between 8.27 and $26.7 \%$ of the total soil phosphorus resources (Table 5). The smallest contribution was found in the moorsh horizons (M1), and the highest in the peat ones. This fraction is represented by the most stable organic and mineral forms of phosphorous without any significant importance for the activation of this element in soils (Jordan et al. 2007, Becher et al. 2018).

\section{CONCLUSIONS}

The effect of the organic matter transformation in the studied Murshic Histosols was a significant increase in the phosphorus content and narrowing the carbon to phosphorus (TC/TP) ratio. The secondary transformation process influenced the large profile diversity of the separated phosphorus forms in the profile of investigated soils. This process contributed to the increase in the share of available phosphorus forms $\left(\mathrm{NH}_{4} \mathrm{Cl}\right.$ $\mathrm{P}$ ), forms bound on the surface of iron (III) and manganese (IV) oxides and hydroxides (redox$\mathrm{P})$, released under reducing conditions as well as mineral (mHCl-P) and organic (oHCl-P) forms separated by $0.5 \mathrm{M} \mathrm{HCl}$. In the studied soils, the phosphorus compounds released were primarily bound by humic substances as well as iron, manganese and aluminum soil compounds.

A significant accumulation of phosphorus in the investigated moorsh horizons (M1, M2, M3) can be considered a potential threat to the natural environment of the studied area, i.e. the Liwiec river valley. An important mechanism that increases the risk of phosphorus migration may be the reduction of the chemical substances containing phosphorus when the area will be rehydrated.

\section{REFERENCES}

1. Bader C., Müller M., Schulin R., Leifeld J. 2018. Peat decomposability in managed organic soils in relation to land use, organic matter composition and temperature. Biogeosciences, 15, 703-719.

2. Balemil T., Negisho K. 2012. Management of soil phosphorus and plant adaptation mechanisms to phosphorus stress for sustainable crop production: a review. Journal of Soil Science and Plant Nutrition, 12, 3, 547-561.

3. Becher M. 2013. Organic matter transformation degree in the soils of the upper Liwiec River [In Polish]. Rozprawa naukowa, 125, Wyd. UPH, Siedlce.

4. Becher M., Pakuła K., Pielech J., Trzcińska E. 2018. Phosphorus resources and fractions in peat-muck soils. Environmental Protection and Natural Resources, 29, 3(77), 1-6.

5. Forsmann D. M., Kjaergaard C. 2014. Phosphorus release from anaerobic peat soils during convective discharge - Effect of soil Fe: P molar ratio and preferential flow. Geoderma, 223-225, 21-32.

6. Glina B., Gajewski P., Kaczmarek Z., Owczarzak W., Rybczyński P. 2016. Current state of peatland soils as an effect of long-term drainage - preliminary results of peatland ecosystems investigation in the Grójecka Valley (central Poland). Soil Science Annual, 67, 1, 3-9.

7. Graham S.A., Craft Ch. B., McCormick P.V., Aldous A. 2005. Forms and accumulation of soil $P$ in natural and recently restored peatlands-Upper Klamath Lake, Oregon, USA.Wetlands, 25, 3, 594-606.

8. Ilnicki P., Szajdak L. W. 2016. Peatland disappearance [In Polish]. Wydawnictwo Poznańskiego Towarzystwa Przyjaciół Nauk, Poznań.

9. Jordan S., Velty S., Zeitz J. 2007. The influence of degree of peat decomposition on phosphorus binding forms in fens. Mires and Peat, 2, 1-10.

10. Kalembasa D., Becher M. 2010. The content of phosphorus in grassland soils of the Liwiec River Valley on Siedlce Upland [In Polish]. Water-Environment-Rural areas, 10, 3 (31), 107-117.

11. Kang J., Hesterberg D., Osmond D.L. 2009. Soil organic matter effects on phosphorus sorption: A path analysis. Soil Science Society of America Journal, 73, 2, 361-366.

12. Łachacz A., Kalisz B. 2016. Polish National Committee of International Peatland Society - history, 
activity, achievements [In Polish]. Wyd. UWM, Olsztyn.

13. Litaor M. I., Reichmann O., Auerswald K., Haimand A., Shenker M. 2004. The geochemistry of phosphorus in peat soils of a semiarid altered wetland. Soil Science Society of America Journal, 68, 6, 2078-2085.

14. Meissner R., Leinweber P., Rupp H., Shenker, Litaor M.I., Robinson S., Schlichting A., Koehn J.2008. Mitigation of diffuse phosphorus pollution during rewetting of fen peat soils: A Trans-European case study. Water, Air, and Soil Pollution, 188, 1-4, 111-126.

15. Otabbong E.,Fristedt A., Otabbong I. 2009. Phosphorus status, disposition and seasonal dynamics in the Swedish Kristianstad Riparian Histosol Wetlands. Acta Agriculturae Scandinavica, Soil \& Plant Science, 59, 2, 179-188.

16. Riet Van De B.P., Hefting M.M., Verhoeven J.T.A. 2013. Rewetting drained peat meadows: risks and benefits in terms of nutrient release and greenhouse gas exchange. Water Air and Soil Pollution, 224.

17. Sapek B. 2012. Phosphorus sorption properties of deposits from peat-muck soil profile in the Kuwasy object. Journal of Water and Land Development, $16,61-66$

18. Sapek B. 2014.Soil phosphorus accumulation and release - sources, processes, causes [In Polish]. Water-Environment-Rural areas, 14 (45), 77-100.

19. SSSP 2011. Soil Science Society of Poland, Polish Soil Classification [In Polish].Soil Science Annual, $62,3$.

20. Worrall F, Moody C. S., Clay G. D., Burt T., and Rose R. 2016. The total phosphorus budget of a peat-covered catchment. Journal of Geophysical Research: Biogeosciences, 121, 7, 1814-1828.

21.Zak D., Gelbrecht J., Zerbe S., Shatwell T., Barth M., Cabezas A., Steffenhagen P. 2014. How helophytes influence the phosphorus cycle in degraded inundated peat soils - Implications for fen restoration. Ecological Engineering, 66, 82-90. 